\title{
THE FULL OR PARTIAL REPLACEMENT OF COMMERCIAL MARINE ENGINE OIL WITH BIO OIL, ON THE EXAMPLE OF LINSEED OIL
}

\author{
Malgorzata Malinowska \\ Gdynia Maritime University, Department of Marine Propulsion Plants \\ Morska Street 81-87, 81-225 Gdynia, Poland \\ tel.: +48585586371, fax: +48585586399 \\ e-mail:m.malinowska@wm.umg.edu.pl
}

\begin{abstract}
The bio-oils are considered to sustainable, alternative and environmentally friendly source of lubricants compared to commercial engine oils, on the base a mineral, synthetic or semi-synthetic. They are obtained from natural raw material (vegetable or animal oils), which are renewable and non-toxic to humans, living organisms and environment. The vegetable oils called green oils, natural oils, bio-oils or natural esters. They can be obtained from plant seeds, that may be consumed - edible oils (for instance: rapeseed oil) or which cannot be consumed - inedible (for example: linseed oil).

The conducted research into linseed oil and its different quantity additives (25\% and $50 \%)$ to commercial marine mineral oil intended for a medium-speed 4-stroke, trunk marine engine (i.e. Marinol RG 1240). The flash point and dependence of viscosity and temperature were compared and assess. It has been proven that vegetable oils have a high ignition temperature and very small viscosity change in the range of temperatures presented, i.e. high viscosity index.

According to the results, it can be recommended the addition of $25 \%$ linseed oil in the base lubricant is the relevant for lubricating a medium speed 4-stroke marine engine. The vegetable additives can improve a viscosity index a lube oil, and they will be positively affected environmental protection.
\end{abstract}

Keywords: bio-lubricant, vegetable oil, linseed oil, engine oil, marine, mineral oil, inedible oil, viscosity, flash point

\section{Introduction}

The lubricants are formulated from a range of base fluids (above 80\%) and chemical additives (max. 20\%). Depending on the origin of the base oil, lubricants might be categorized as mineral (crude petroleum), synthetic (polyalphaolefins, polyalkylene glycols, synthetic esters, silicones, etc.), semi-synthetic or as natural oils (plant and animal fats) $[1,12,15]$. Currently, mineral oils are the most commonly used in the industry, also in marine. They have the longest an operating life, which decreases the frequency of breakdown time of the engine [4].

However, petroleum-base lubricants have very poor biodegradability, release heavy metals and sulphur compounds into the environment, and they are non-renewable [11]. The problem especially concerns used oils, which have to dispose without harmful effects on the nature. In order to care of Planet Earth the demand to produce new environmentally acceptable lubricants from other resources rather than crude oil. The solution of presented issue can be bio-lubricants, which have desirable properties: biodegradability, non-toxic and renewable. Currently, interest in research on natural-based oils is increasing $[11,13,16]$.

The objective of this work is to study the viscosity-temperature dependence and flash point of linseed oil and its blends with commercial marine mineral oil.

\section{Marine engine lubrication system}

The lubricating system with proper lubricant is a crucial in all internal combustion engines. In the case of marine engines, the circulating oil system consists of oil sump, pumps, filters and cooler. The tasks of lubricating oil include $[10,15]$ : the formation of oil film between the moving 
parts, assisting in cooling, keeping the compression ratio, reducing corrosion, filling in all micro ridges on the surface, sealing the combustion chamber, dissolving and washing the sediment, suppressing the vibration and decreasing noisiness.

In the engine, the lube oil degrades and about fifty percent of it is consumed in the process of normal operation at engine [13]. Unfortunately, the rest of oil (named waste oil) becomes useless and has to be exchanged. As it contains many different contaminants from the working environment, such as: residual components of fuels, cooling agent, solids from wear processes along with corrosion products and dirt, soot, combustion products etc. [9]. The waste oil creates enormous problems if will be wrongly disposed. The most dangerous are illegal discharges at sea, which may cause [13]:

- death of marine life,

- change of physicochemical properties of seawater,

- create of film of oil on the surface of water, which prevent the replenishment of dissolved oxygen thereby hamper aquatic life, impair photosynthetic processes and block sunlight.

In automotive motors, the quantity of waste oil is little (max. couple of litres), but in the case of large marine engines, the problem is a very significant.

This article concerns a lube oils for a medium-speed 4-stroke, trunk marine engines, which are continuously exposed to combustion products. In the case of marine engines powered by light fuel used lubricants with kinematic viscosity range between $9.3-16.3 \mathrm{~mm}^{2} / \mathrm{s}$ (at $100^{\circ} \mathrm{C}$ ). The flash point should be no less than $180^{\circ} \mathrm{C}$.

\section{Bio-lubricants}

Bio-lubricant is defined as a lubricant obtained from natural raw materials, which are renewable and non-toxic for humans, living organisms and environment. Bio-lubricants may originate from vegetable and animal oils, but this article concerns only vegetable oils. The vegetable oils called green oils, natural oils or natural esters [11]. They can be obtained from plant seeds, that may be consumed - edible oils (sunflower, olive, coconut, soybean, palm, corn, peanut, canola etc.) or which cannot be consumed - inedible (rice bran, neem, mahua, karanja, jatropha, linseed, castor and other) [2].

They are mainly triglycerides, which are glycerol molecules that have three long chain polar fatty acids attached at the hydroxyl groups via ester linkages $[3,14,16]$. The most common fatty acids encountered in the composition of oils are saturated acids with 12 (lauricacids), 14 (myristicacids), 16 (palmiticacids) or 18 (stearic acids) carbon atoms and $\mathrm{C}_{18}$ polyunsaturated acids with, 1 (oleicacids), 2 (linoleicacids) or 3 (linolenic acids) double bonds [12]. It is worth noting that green oils have unstable nature, due to content of free acid [1].

It is generally acknowledged that the green oils used as lubricants, have followed advantages (beside the mentioned in introduction: biodegradability, non-toxic and renewable) [8]: very low volatility, excellent temperature- viscosity properties, good lubricity, high solubilizing power for polar contaminants and additive molecules, blends well with the other type of oils, non-reacts with sealing materials, high flash and fire point etc.

Obviously, green oils also have certain drawbacks: they are characterized by limited thermal and oxidative stability, low hydrolytic stability, poor corrosion protection, gumming effect, high frictional coefficient and high pour point $[4,8]$.

The listed advantages and disadvantages of bio-lubricants, are only general assumptions, because the detailed chemical and physical properties of selected type of vegetable oil mainly depend on the composition of unsaturated fatty acids (chain number and length, presence, position and shape of double bonds), which in turn depend on type of plant, the genetic modification of the crops, climate of cultivation and so forth [2]. Comparing two vegetable oils, coconut and rapeseed, it is clearly visible that they have different characteristics. During studies' perform, content of fatty acid in different type of oils should be known (see Tab. 1). 
Tab. 1. Fatty acids composition of vegetable oils [1,2]

\begin{tabular}{|c|c|c|c|c|c|c|c|c|}
\hline \multirow{2}{*}{$\begin{array}{c}\text { Type of } \\
\text { vegetable }\end{array}$} & \multicolumn{8}{|c|}{ Fatty acids } \\
\hline & $\begin{array}{l}\text { Lauric } \\
(12: 0)\end{array}$ & $\begin{array}{c}\text { Myristic } \\
(14: 0)\end{array}$ & $\begin{array}{c}\text { Palmitic } \\
(16: 0)\end{array}$ & $\begin{array}{c}\text { Stearic } \\
(18: 0)\end{array}$ & $\begin{array}{l}\text { Oleic } \\
(18: 1)\end{array}$ & $\begin{array}{c}\text { Linoleic } \\
(18: 2)\end{array}$ & $\begin{array}{c}\text { Linolenic } \\
(18: 3)\end{array}$ & Others \\
\hline $\begin{array}{l}\text { Number of } \\
\text { unsaturated } \\
\text { bonds }\end{array}$ & 0 & 0 & 0 & 0 & 1 & 2 & 3 & \\
\hline Sunflower oil & - & - & 7 & 5 & $20-25$ & $63-68$ & 0.2 & \\
\hline Safflower oil & - & - & $5-7$ & $1-4$ & $13-21$ & $73-79$ & - & \\
\hline Soybean oil & - & - & $11-12$ & 3 & 24 & $53-55$ & $6-7$ & \\
\hline Corn oil & - & - & $11-13$ & $2-3$ & $25-31$ & $54-60$ & 1 & \\
\hline Cottonseed oil & - & 1 & $22-26$ & $2-5$ & $15-20$ & $49-58$ & - & \\
\hline Rapeseed oil & - & - & $4-5$ & $1-2$ & $56-64$ & $20-26$ & $8-10$ & $\begin{array}{c}9.1 \\
(20: 1)\end{array}$ \\
\hline Canola oil & & & 2.5 & 1 & 64.4 & 22.2 & 8.2 & \\
\hline Peanut oil & - & - & $10-11$ & $2-3$ & $48-50$ & $39-40$ & - & \\
\hline Linseed oil & - & - & $4-5$ & $2-4$ & 19.1 & $12-18$ & 56.6 & \\
\hline Olive oil & - & - & 13.7 & 2.5 & 71 & 10 & $0-1.5$ & \\
\hline Coconut oil & $44-52$ & $13-19$ & $8-11$ & $1-3$ & $5-8$ & $0-1$ & - & \\
\hline Palm oil & - & 1 & $37-41$ & $3-6$ & $40-45$ & $8-10$ & - & \\
\hline
\end{tabular}

The composition of fatty acids in oil decides of its following properties [17]:

- viscosity - the increase with higher carbon chain length of fatty acids and decrease with increase in unsaturated bonds. Natural oils with saturated bonds are much more effective lubricants than oils with unsaturated fatty acids [6];

- flash point - the increase in unsaturated bonds causes increase the ignition temperature [17];

- melting temperature - the presence of double bonds and the shorter carbon chain of fatty acid, the cause a lower melting temperature it has. The linoleic and linolenic acids have more double bonds, and they maintain in liquid state even at low temperatures [17]. For example, coconut oil does not have linoleic and linolenic acids, so it is a solid at ambient temperature;

- toxic - for vegetable oils, the higher the percentage of unsaturation, the better they will be in preparing environmentally acceptable lubricants (non-toxic) or additives for lubricants [2].

The author previously researched the effects of the additive of rapeseed oil on the viscosity of marine engine oil - Marinol RG 1240 [8, 11]. In this article, chosen linseed oil because of the high content of linolenic acids and inedible character is presented. It is worth mentioned that linseed oil was used in technique since the 15 th century, usually as protective coating.

\section{Oil samples}

The research was conducted using samples of commercial mineral oil - Marinol RG 1240, linseed oil and their blends. Description of all oil samples are shown in Tab. 2.

Tab. 2. Composition of studied oils

\begin{tabular}{|c|c|}
\hline Samples & Composition \\
\hline Sample 1 & $100 \%$ Marinol RG 1240 \\
\hline Sample 2 & $100 \%$ linseed oil \\
\hline Sample 3 & $25 \%$ - linseed oil and $75 \%$ Marinol RG 1240 \\
\hline Sample 4 & $50 \%$ - linseed oil and $50 \%$ Marinol RG 1240 \\
\hline
\end{tabular}


The every lubricating oil can be evaluated through different basic parameters: viscosity, density, flash point, pour point, base number etc. Whereas vegetable oils have a non-standard parameter, it is the iodine value (IV). The iodine value is a measure of fatty acid components or unsaturation as either olefins and/or aromatics [15]. Larger IV values indicate a greater degree of unsaturation per vegetable oil triglyceride. Therefore, can classified oils as: drying oils (IV > 130), semi-drying oils $(100<$ IV $<130)$, or non-drying oils (IV < 100). The substances from "drying" group are more susceptible it is to functionalization and can easily be chemically modified [2]. The chosen parameters of researched oils are shown in Tab. 3.

Tab. 3. The selected parameters of linseed oil and Marinol RG1240

\begin{tabular}{|c|c|c|c|c|c|c|c|}
\hline Type of oil & $\begin{array}{c}\text { Iodine } \\
\text { value }\end{array}$ & $\begin{array}{c}\text { Pour } \\
\text { point }\left[{ }^{\circ} \mathrm{C}\right]\end{array}$ & $\begin{array}{c}\text { Kinematic } \\
\text { viscosity } \\
\text { at } 100^{\circ} \mathrm{C} \\
{\left[\mathrm{mm}^{2} / \mathrm{s}\right]}\end{array}$ & $\begin{array}{c}\text { Kinematic } \\
\text { viscosity at } \\
40^{\circ} \mathrm{C} \\
{\left[\mathrm{mm}^{2} / \mathrm{s}\right]}\end{array}$ & $\begin{array}{c}\text { Flash } \\
\text { point }\left[{ }^{\circ} \mathrm{C}\right]\end{array}$ & $\begin{array}{c}\text { Density at } \\
15^{\circ} \mathrm{C} \\
{\left[\mathrm{g} / \mathrm{cm}^{3}\right]}\end{array}$ & $\begin{array}{c}\text { Viscosity } \\
\text { index }\end{array}$ \\
\hline Linseed oil & $168-204$ & -15 & 6.95 & $26-29$ & 241 & 0.938 & 248 \\
\hline $\begin{array}{c}\text { MARINOL } \\
\text { RG 1240 }\end{array}$ & - & -18 & 14.6 & 149.1 & 230 & 0.899 & 96 \\
\hline
\end{tabular}

The linseed oil has a high viscosity index (248), minimum sulphur content, higher concentration of linolenic acid and it is biodegradable. The research results conducted by [4], shown that "linseed oils are characterized by high levels of corrosiveness and oxidative stability". It is most likely this is explained by the fact that the polymerization processes of its molecules are predominant over the hydrolysis processes. Linseed oil among the group of inedible oils, which are comparatively less expensive [2] and they allow reducing problems related debate on use of the food as source of energy.

\section{Experiments}

The aim of this work was to compare and to assess two basic physicochemical properties: flash point and dependence of viscosity and temperature of oil Marinol RG 1240, linseed oil and their blends:

- the flash point gives an indication of the presence of volatile components in the oil and it is the temperature which oil must reach under specified test conditions to give off sufficient vapour to form a flammable mixture with air [15],

- the viscosity of a fluid is a measure of its resistance to flow. It is the measure of internal friction in a fluid, which acts as a resistance to change of molecule position in moving fluid exposed to shear stress $[5,7]$.

\subsection{Flash point measurements}

To conduct the measurement used the ERAFLASH device, which uses the closed-cup method. The temperature measuring range of device lies between $-25^{\circ} \mathrm{C}$ and $+420^{\circ} \mathrm{C}$. The ignition in the Eraflash starts from electric arc and the measure of ignition is the increase of exhaust gasses pressure. The results of the flash point test are shown in Tab. 4.

The flash point of Marinol RG 1240 is equal 231.5 degrees Celsius. The linseed oil has a little lower value of mentioned temperature $-220.9^{\circ} \mathrm{C}$. For subsequent oil blends, the ignition point accounting $225.2^{\circ} \mathrm{C}$ (sample with $25 \%$ linseed oil) and $223.3^{\circ} \mathrm{C}(50 \%$ linseed oil). It has to be pointed out that linseed oil has greater influence on the behaviour of ignition temperature of blends. Before make a researching, it was expected that flash point for blend of $50 \%$ mineral oil and $50 \%$ linseed oil will be around $226.2((231.5+220.9) / 2)$. 
Tab. 4. The results of flash point measurements

\begin{tabular}{|c|c|c|c|c|}
\hline Samples & Sample 1 & Sample 2 & Sample 3 & Sample 4 \\
\hline Flash point $\left[{ }^{\circ} \mathrm{C}\right]$ & 231.5 & 220.9 & 225.2 & 223.3 \\
\hline
\end{tabular}

Bio-lubricants with other fatty acids composition have a usually higher flash point than mineral oils (for example rapeseed oil [11]). However, a linseed oil is comparable to petroleum-based lubricants and fulfils the required the minimum ignition point $\left(180^{\circ} \mathrm{C}\right)$.

\subsection{Viscosity measurements}

To test the dependence of viscosity and temperature at $5^{\circ} \mathrm{C}$ to $95^{\circ} \mathrm{C}$ range, researchers used the rheometer Haake Mars III of Thermo Scientific Company. The tests were conducted using the cone-plate system. During tests, the parameters of rheometer were as follows:

- shear rate $\gamma=100 \mathrm{l} / \mathrm{s}$,

- temperature range from $5^{\circ} \mathrm{C}$ to $100^{\circ} \mathrm{C}$,

- time of one test $\mathrm{t}=5 \mathrm{~min}$.

The viscosity curves dependencies from temperature were determined for each oil in three measuring cycles in full temperature range; designated points of specification constitute the mean value of these measurements. All samples behave as regular liquids and in all tested samples the viscosity decreases while the temperature rises at completely tested range (Fig. 1).

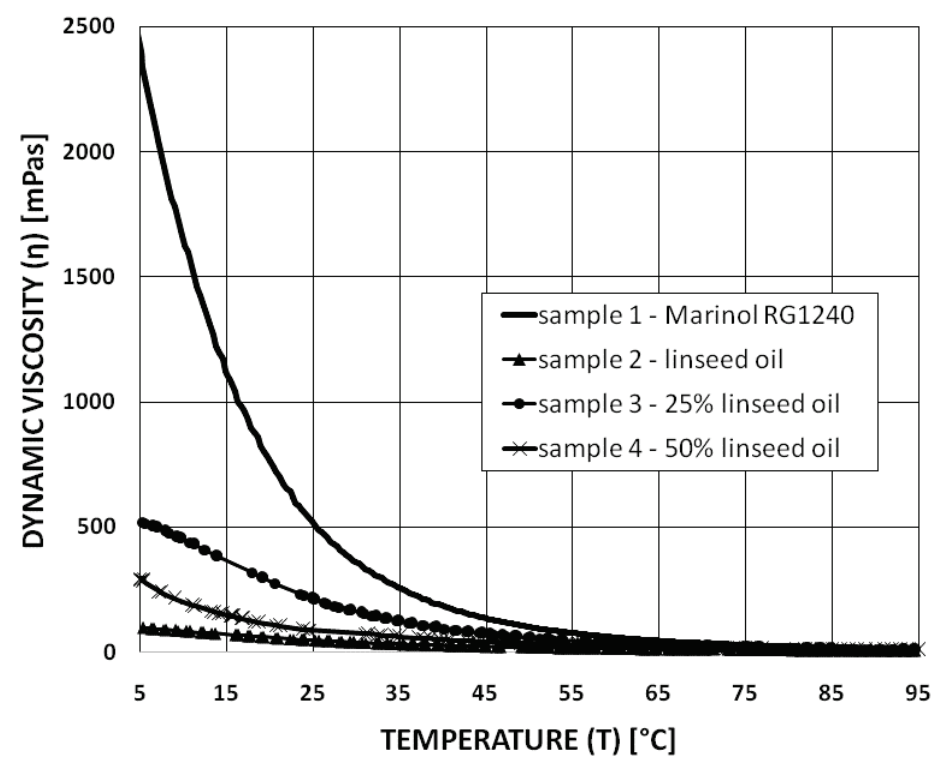

Fig. 1. The graph of viscosity versus temperature for all samples

In the case of research of viscosity-temperature characteristic visible also (just as for flash point) is strong effect of vegetable oil on the samples 3 and 4 . Before starting of investigation, equal influent of mineral and linseed oil had been estimated. However, natural ester proved to be dominant. For sample with one quarter of vegetable oil (in low temperature), the characteristic diagram is a definitely more similar to linseed oil curve.

The results are also presented in a Tab. 5, where shown viscosity for selected temperatures as well as the percentage difference between commercial oil (Marinol RG 1240) and other samples.

The very important property of linseed oil, it is smaller viscosity change in the range of presented temperatures (between $5^{\circ} \mathrm{C}$ and $100^{\circ} \mathrm{C}$ ), for Marinol RG 1240 this change is equal 2383 degrees, however for linseed oil it is only 90 degrees, thus confirmed a higher viscosity index. For samples 3 and 4, this change it amounts to 520.5 and 288.2. 
Tab. 5. The dynamic viscosity for selected temperatures and percentage difference of viscosity between sample 1 (Marinol RG 1240) and other samples

\begin{tabular}{|c|c|c|c|c|c|c|c|}
\hline \multirow{2}{*}{ Temperature } & \multicolumn{7}{|c|}{ Dynamic viscosity [mPas] } \\
\cline { 2 - 8 } & $\begin{array}{c}\text { Marinol } \\
\text { RG 1240 }\end{array}$ & $\begin{array}{c}\text { Linseed } \\
\text { oil }\end{array}$ & Difference & $\begin{array}{c}25 \% \\
\text { linseed oil }\end{array}$ & Difference & $\begin{array}{c}50 \% \\
\text { linseed oil }\end{array}$ & Difference \\
\hline $5^{\circ} \mathrm{C}$ & 2400 & 97.5 & $-95.9 \%$ & 530 & $-77.9 \%$ & 296 & $-87.7 \%$ \\
\hline $40^{\circ} \mathrm{C}$ & 185 & 28 & $-84.9 \%$ & 94 & $-49.2 \%$ & 51.4 & $-72.2 \%$ \\
\hline $60^{\circ} \mathrm{C}$ & 59 & 15.2 & $-74.2 \%$ & 38 & $-35.6 \%$ & 25 & $-57.6 \%$ \\
\hline $100^{\circ} \mathrm{C}$ & 11.8 & 6.1 & $-48.3 \%$ & 9.5 & $-19.5 \%$ & 7.8 & $-33.9 \%$ \\
\hline
\end{tabular}

According to the Wärtsilä company, for a medium-speed 4-stroke, trunk marine engines, the maximum variation of viscosity of motor oil at $100{ }^{\circ} \mathrm{C}$ is $-20 \% /+25 \%$ and at $40^{\circ} \mathrm{C}$ is $25 \% /+45 \%$ [18]. The blend of mineral oil with $25 \%$ linseed oil almost include in these criteria. In addition to that, during the exploitation, high temperature acting on vegetable oil affects the increase of its viscosity. The impact of the plant additives up to $25 \%$ is expected to be improvement characteristics of viscosity. Engine operators can make small refills of lubricating system with vegetable oils without worrying about its influence on the of mineral oil viscosity.

\section{Conclusion}

Currently, ecological sources of energy are emerging as a new trend in industry, especially marine industry. Many scientific and technical centres look for an alternative substance for traditional petroleum products. The one of them are natural oils, which can be used in lubricating systems of marine engines. Bio-lubricants are nontoxic, biodegradable, and they have a high viscosity index, better wear performance, higher flash point and lower pour point and cloud point than commercial mineral lubricants.

Unfortunately, green oils have disadvantages, for examples they can react with oxygen to form undesirable products, which reduces the lubricant properties, poor corrosion protection, susceptibility to hydrolytic breakdown, gumming effect etc. On the other hand, the chosen linseed oil is unique, because of characterized by high levels of corrosiveness stability and oxidative stability. "This property makes it possible to use linseed oil as an additive, which forms on friction surfaces under the effect of a high temperature and pressure and protective anti-wear films"[4].

The researches of linseed oil, it showed that has very high viscosity index, proper flash point and good thermal stability. It has to be pointed out that linseed oil has greater influence on the parameters of blends mineral and vegetable oils. The characteristics of viscosity of pure linseed oil are not sufficient for lubrication of medium-speed marine engine, but it can constitute a good ecologic additive.

According to the experimental result, it can be recommended the addition of $25 \%$ linseed oil in the base lubricant of marine engines. The application of linseed oil or other inedible oils can contribute to reduce the global demand of mineral lubricants and helping different countries (especially developing) to decrease the environmental impact of crude oil.

In conclusion, the bio-based lubricants have advantages in terms ecological, though it is slightly expensive and need more research must be done to improve their physical properties. However, the vegetable oils - especially non-edible are the viable alternative.

\section{References}

[1] Arianti, N., Annisa, Widayat W., A Review of Bio-lubricant Production from Vegetable Oils Using Esterification Transesterification Process, MATEC Web of Conferences 156, pp. 1-7, 2018. 
[2] Gobinda, K., Pranab, G., Brajendra, S., Chemically Modifying Vegetable Oils to Prepare Green Lubricants, Lubricants, Vol. 5, No. 4, 44, pp. 1-17, 2017.

[3] Kania, D., Robiah, Y., Rozita, O., Suraya, A. R., Badrul, M. J., A review of biolubricants in drilling fluids: Recent research, performance, and applications, Journal of Petroleum Science and Engineering, 135, pp. 177-184, 2015.

[4] Kavaliova, I. N., Grigoriev, F. A., Corrosive Action and Oxidation of Vegetable Oils Used in Lubricants, Journal of Friction and Wear, 39(6), pp. 535-538, 2018.

[5] Landsdown, A. R., Lubrication and Lubricant selection - A practical Guide, Mechanical Engineering Publications, Bury St. Edmunds, London 1996.

[6] Li, B., Li, C., Zhang, Y., Wang. Y., Jia, D., Min, Y., Grinding temperature and energy ratio coeffcient in MQL gringing of high-temperature nickel-base alloy by using different vegetable oils as base oil, Chinese Journal of Aeronautics, 4(29), pp. 1084-1095, 2016.

[7] Ljubas, D., Krpan, H., Matanović, I., Influence of engine oils dilution by fuels on their viscosity, flash point and fire point, Nafta: exploration, production, processing, petrochemistry, 61(2), pp. 73-79, Hrčak 2010.

[8] Malinowska, M., The effects of the addition of vegetable oil on the viscosity of used marine engine oil Marinol RG 1240, New Trends in Production Engineering, 1, pp. 479-485, 2018.

[9] Malinowska, M., Spectroscopic study and analysis of the content of residue elements in Marinol RG 1240 oil after working in various types of engines, Zeszyty Naukowe Akademii Morskiej w Gdyni, Nr 100, pp. 131-140, 2017.

[10] Malinowska, M., The evaluation of viscosity properties of engine oil-Marinol RG 1240 after working in various types of engines, Journal of KONES Powertrain and Transport 25(1), pp. 275-283, 2018.

[11] Malinowska, M., The full or partial replacement of mineral marine engine oil with vegetable oil. on the example of rapeseed oil, Journal of KONES, Vol. 24, No. 1, pp. 247-253, 2017.

[12] Mills, J. S., White, R., Oils and fats. In: The organic chemistry of museum objects, Oxford: Butterworth and Heinemann, pp. 31, 1994.

[13] Rahman, M. M., Siddiquee, T. A., Samdani, S., Kabir, K. B., Effect of operating Variables on Regeneration of Base oil from Waste oil by Conventional Acid-clay Method, Journal of Chemical Engineering, 12, pp. 24-27, 2008.

[14] Shahabuddin, M., Masjuki, H. H., Kalam, M. A., Bhuiya, M. M. K., Mehat, H., Comparative tribological investigation of bio-lubricant formulated from a non-edible oil source (Jatropha oil), Industrial Crops and Products, Vol. 47, pp. 323-330, 2013.

[15] Speight, J. G., Handbook of Petroleum Product Analysis, A John Wiley \& Sons Inc. Hoboken, New Jersey 2015.

[16] Stachowiak, N. G., Vegetable oil-based lubricants - a review of oxidation, Tribol, Int, 40, pp. 1035-1046, 2007.

[17] Szczypska, M., Golimowski, W., Properties comparison of vegetable oils as lubricants, Journal of Research and Applications in Agricultural Engineering, Vol. 63, No. 1, pp. 121$125,2018$.

[18] www. din.unina.it/atena/20100513tribologia02hlededavia.pdf, (May 2019).

Manuscript received 11 June 2019; approved for printing 20 September 2019 